DOI: $10.5277 /$ epe 160301

\title{
REMOVAL OF METHYLENE BLUE FROM AQUEOUS SOLUTIONS WITH NATURAL OLIVE POMACE MODIFIED WITH ULTRASOUNDS AND ACID
}

\begin{abstract}
Removal of methylene blue (MB) from aqueous solution by raw olive pomace (ROP) which is a waste of industrial olive oil and olive pomace modified with ultrasounds and acid (MOP) has been investigated. It was found that the data for ROP and MOP were well fit to the Freundlich isotherm model ( $R^{2}$ equal to 0.864 and 0.834 , respectively). As a result; it was determined that raw olive pomace can be used for the removal of methylene blue dye $\left(K_{F}=10.08 \mathrm{mg} / \mathrm{g}\left(\mathrm{dm}^{3} / \mathrm{mg}\right)^{1 / n}\right)$ and modified olive pomace had high adsorption capacity for $\mathrm{MB}\left(K_{F}=73.08 \mathrm{mg} / \mathrm{g}\left(\mathrm{dm}^{3} / \mathrm{mg}\right)^{1 / n}\right)$.
\end{abstract}

\section{INTRODUCTION}

Many dyestuff are commonly used in industrial fields such as textile, paper, leather, plastic, food, dye factories, etc. Since dyed wastewater sourced from these sectors has a toxic nature, it is risky in terms of human and environmental health. Moreover, this kind of coloured wastewater also causes aesthetic problems in the fields where it is discharged [1]. It not only breaks the natural aesthetic of the environment but also has poisonous effect for aquatic life. It reduces transparency of water, changes photosynthetic activity, affects aquatic life and food chain and might have carcinogenic and mutagenic effects. Recently, treatment techniques such as coagulation, Fenton process, electro-Fenton process, chemical or electrochemical precipitation, biological treatment processes, ozonation, adsorption [1, 2], etc. are involved in order to decrease the detrimental effects of these dyestuff. Among these methods, the Fenton process, electroFenton process, chemical and electrochemical precipitation produce chemical sludge containing toxic and heavy metal compounds. Disposal of this sludge seriously in-

${ }^{1}$ Department of Environmental Engineering, Nevsehir Hacı Bektas Veli University, 50300 Nevsehir, Turkey, e-mail: ekalipci@nevsehir.edu.tr 
creases the cost of treatment. Ozonation is a process which requires high cost and qualified employee. Moreover, since ozone is not selective, it will be in a tendency to react with all pollutants in wastewater. This will increase the ozone need for adequate treatment efficiency and result in increase in the cost of treatment. Generally too little decolorization can be performed by biological processes [3]. Among current technologies, the most suitable technology for the removal of dyes and other pollutants from wastewater is adsorption [4]. The most important preference of adsorption process contrary to these mentioned methods is that it is a cheap and effective treatment method by using natural adsorbent materials [5]. As well as the fact that adsorption is an effective treatment method for the removal of pollutants from water, if the adsorbents used are environmentally friendly, cheap and easily available, then the economical aspect of adsorption is also revealed [6].

Recently, wastewater treatment with ultrasounds has become an attractive treatment technique [7] and an increase is observed in applications where ultrasounds are used. Especially the effect of ultrasound modification on the capacity of adsorption has been searched recently. The studies indicated that ultrasound modification increased the adsorption capacity [8]. Ultrasonication has an accelerating effect in chemical process due to acoustic cavitation. For ultrasonic frequencies lower than $100 \mathrm{kHz}$, ultrasonic radiation creates very strong hydromechanics shear forces. These forces increase and develop pores on the surface of the adsorbent material and expand the surface for adsorption. Thus they increase the adsorption capacity of the material [9].

Methylene blue was chosen as a target contaminant to characterize the adsorptive properties of olive pomace as it is a common cationic dye used in the medical, factories, textile and printing industries. In this study, raw olive pomace, which is cheap, abundantly available and does not include toxic materials, is used as an alternative treatment material after modification with ultrasounds and acid for the removal of methylene blue from aqueous solution. Pomace which is a waste material of olive oil industry can be used as an adsorbent for the removal of pollutants from aqueous solutions [10]. These materials might enhance the efficiency of adsorption after modification. In Mediterranean countries such as Greece, Italy, Lebanon, Portugal, Spain, Syria, Tunisia and Turkey, where olive oil industry is present [11], the usability of pomace which develops as an abundantly available industrial waste was searched with this new modification method.

\section{MATERIALS AND METHODS}

Materials. Solid waste (raw pomace) constituting of oil seed and pulp remaining from olive oil production was used as an adsorbent. Raw olive pomace samples were collected from olive oil production plants in Turkey as pressed and sunny dried disks. Experimental studies were performed by using raw olive pomace (ROP) and modified olive pomace (MOP). The main characteristics of ROP are given in Table 1. The scanning electron microscope (SEM) images of ROP and MOP are shown in Figs. 1a, b, respectively. 
Table 1

Main characteristics of raw olive pomace

\begin{tabular}{|l|c|l|c|}
\hline \multicolumn{1}{|c|}{ Parameter } & Range & \multicolumn{1}{c|}{ Parameter } & Range \\
\hline Moisture, $\%$ & $52.3-71.6$ & Water soluble carbohydrates, $\mathrm{g} \cdot \mathrm{kg}^{-1}$ & $12.0-158.0$ \\
\hline $\mathrm{pH}$, water & $4.45-6.34$ & Water soluble phenols, $\mathrm{g} \cdot \mathrm{kg}^{-1}$ & $6.0-22.7$ \\
\hline Electrical conductivity, $\mathrm{dS} \cdot \mathrm{m}^{-1}$ & $0.83-4.55$ & Phosphorus, $\mathrm{g} \cdot \mathrm{kg}^{-1}$ & $0.8-2.0$ \\
\hline Organic matter, $\mathrm{g} \cdot \mathrm{kg}^{-1}$ & $837.6-968.2$ & Potassium, $\mathrm{g} \cdot \mathrm{kg}^{-1}$ & $7.5-28.9$ \\
\hline Lignin, $\mathrm{g} \cdot \mathrm{kg}^{-1}$ & $320.0-554.3$ & Calcium, $\mathrm{g} \cdot \mathrm{kg}^{-1}$ & $1.5-9.0$ \\
\hline Cellulose, $\mathrm{g} \cdot \mathrm{kg}^{-1}$ & $139.3-247.0$ & Magnesium, $\mathrm{g} \cdot \mathrm{kg}^{-1}$ & $0.8-3.7$ \\
\hline Hemicellulose, $\mathrm{g} \cdot \mathrm{kg}^{-1}$ & $271.3-412.7$ & Sodium, $\mathrm{g} \cdot \mathrm{kg}^{-1}$ & $0.6-1.4$ \\
\hline Total organic carbon, $\mathrm{g} \cdot \mathrm{kg}^{-1}$ & $492.5-538.0$ & İon, $\mathrm{g} \cdot \mathrm{kg}^{-1}$ & $80-1445$ \\
\hline Total nitrogen, $\mathrm{g} \cdot \mathrm{kg}^{-1}$ & $6.8-17.9$ & Copper, $\mathrm{g} \cdot \mathrm{kg}^{-1}$ & $11-27$ \\
\hline C/N ratio & $27.5-71.8$ & Manganese, $\mathrm{g} \cdot \mathrm{kg}^{-1}$ & $6-35$ \\
\hline Total oil, $\mathrm{g} \cdot \mathrm{kg}^{-1}$ & $76.4-192.8$ & Zinc, $\mathrm{g} \cdot \mathrm{kg}^{-1}$ & $12-35$ \\
\hline
\end{tabular}
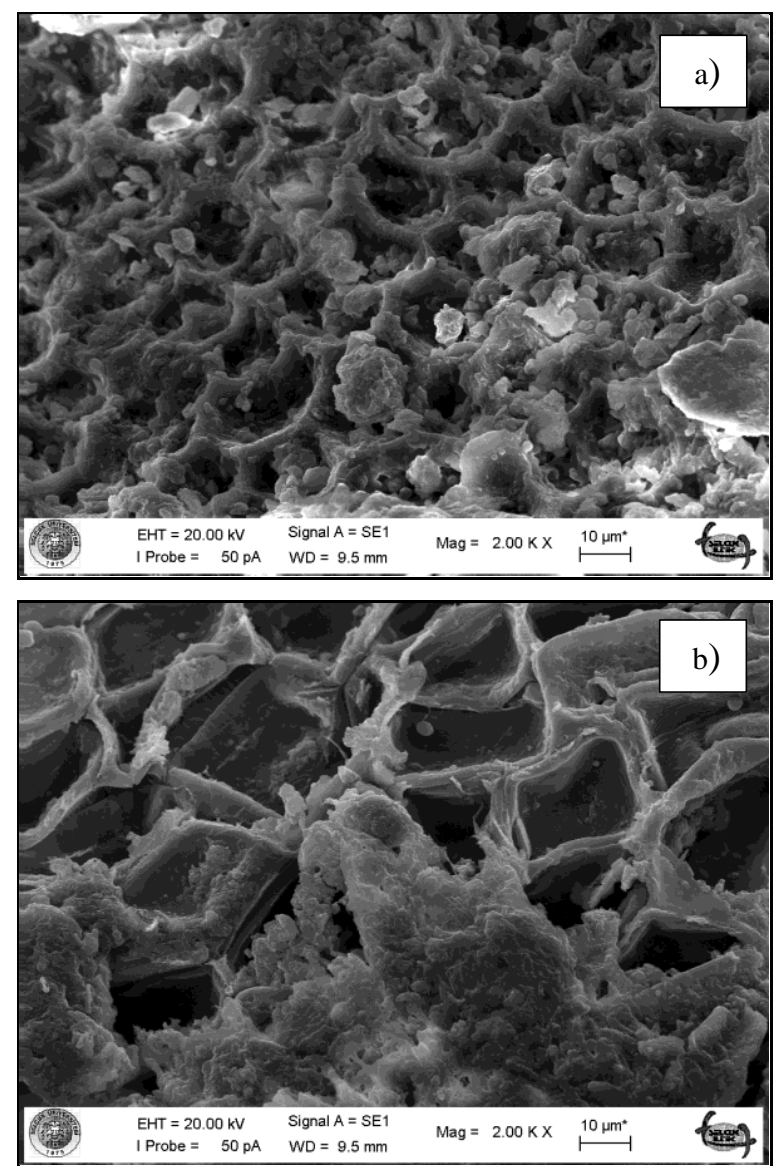

Fig. 1. SEM images of: a) ROP, b) MOP 
The basic dye MB (basic blue 9, C.I. 52015, chemical formula, $\mathrm{C}_{16} \mathrm{H}_{18} \mathrm{C}_{1} \mathrm{~N}_{3} \mathrm{~S} \cdot 3 \mathrm{H}_{2} \mathrm{O}$, $373.90 \mathrm{~g} \cdot \mathrm{mol}^{-1}$ ) was used as such without further purification to prepare the aqueous solution. It has a maximum visible absorbance at $662 \mathrm{~nm}$. The chemical structure of MB (obtained from Carlo Erba) is shown in Fig. 2 [12].

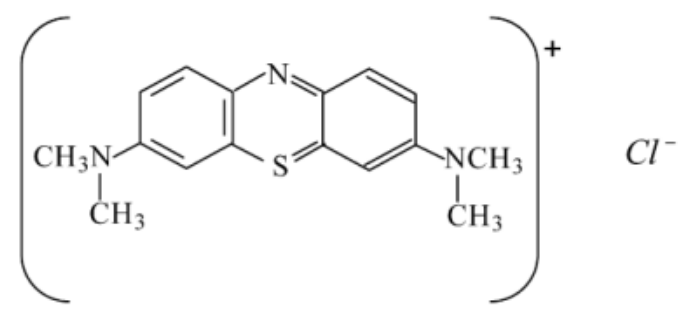

Fig. 2. Chemical structure of MB [12]

Experimental methods via ultrasound modification. Ultrasonic acid modification of raw olive pomace was performed by subjecting $200 \mathrm{mg} / \mathrm{dm}^{3}$ of screened pomace to ultrasound in $500 \mathrm{~cm}^{3}$ of $3 \mathrm{M} \mathrm{H}_{2} \mathrm{SO}_{4}$ solution for $2 \mathrm{~h}$ in ultrasonic water bath at $35 \mathrm{kHz}$ frequency. In order to prevent settlement of pomace in the solution, it was mixed with a mechanical stirrer (Heidoplh Germany) for $2 \mathrm{~h}$ at low-speed. At the end of this period, the mixture was filtered, the material was washed with ultrapure water and then dried in a drying-oven $\left(105^{\circ} \mathrm{C}\right.$ during 1 day). Since particle size of the material is important, it was screened through the same sieves with similar screen openings $(0.25-0.4 \mathrm{~mm})$ and made ready for use. For this modification, Kudos SK $1200 \mathrm{H}$ ultrasonic water bath was used.

Adsorption. Methylene blue solutions were as prepared with ultra-distilled water (MP Minipure Destup). $1 \mathrm{~g}$ of accurately weighed of methylene blue was dissolved in ultra-distilled water to prepare the stock solution $\left(1000 \mathrm{mg} / \mathrm{dm}^{3}\right)$. Experimental solutions of the desired concentration were obtained by successive dilutions. All chemicals used in this study were of analytical-laboratory grade, being purchased from Merck. In the dosage-time experiments, 200, 400,600, and $800 \mathrm{mg} / \mathrm{dm}^{3}$ of ROP and MOP were shaken with $250 \mathrm{~cm}^{3}$ of $\mathrm{MB}$ solution $\left(100 \mathrm{mg} / \mathrm{dm}^{3}\right)$ at desired $\mathrm{pH}$ and temperature at a fixed mixing speed of $250 \mathrm{rpm}$ for $0-300 \mathrm{~min}$. $\mathrm{pH}$ of the solution was adjusted to 6 with $0.1 \mathrm{M} \mathrm{HCl}$ or $0.1 \mathrm{M} \mathrm{NaOH}$ by using a Hach Lange HQ 30D pH-meter with a combined $\mathrm{pH}$ electrode. Adsorption was carried out in a batch system at $30{ }^{\circ} \mathrm{C}$ in the dosage-time experiments.

Pomace samples were screened through sieves between 0.25 and $0.4 \mathrm{~mm}$, washed with distilled water and then used after drying at $105{ }^{\circ} \mathrm{C}$ in a drying oven (JSR JSOF-050). The experiments were performed using $250 \mathrm{~cm}^{3}$ glass flasks with cooling and shaking incubator (JSR JSSI-300 C). After mixing processes, $0.45 \mu \mathrm{m}$ membrane filters (Millipore 
Corp., Bedford, Mass.) were used to separate the sample from the adsorbent. For measurements, a Thermo Scientific Aqua Mate Plus UV-VIS model spectrophotometer was used.

The adsorbed amount of $\mathrm{MB}$ at equilibrium, $q_{e}(\mathrm{mg} / \mathrm{g})$ was calculated by the following equation:

$$
q_{e}=\frac{V\left(C_{0}-C_{e}\right)}{W}
$$

where $C_{0}$ and $C_{e}$ are the initial and equilibrium MB concentrations $\left(\mathrm{mg} / \mathrm{dm}^{3}\right)$, respectively, $V$ is the volume of solution $\left(\mathrm{dm}^{3}\right)$ and $W$ is the dry weight of the added raw olive pomace $(\mathrm{g})$ [13].

The Langmuir isotherm presupposes monolayer adsorption onto a surface containing a finite number of adsorption sites via uniform strategies of adsorption with no transmigration of the adsorbate taking place along the plane of the surface. The linear form of the Langmuir isotherm model represents the following equation [14]:

$$
\frac{C_{e}}{q_{e}}=\frac{1}{Q_{0} b}+\frac{1}{Q_{0}} C_{e}
$$

where $Q_{0}(\mathrm{mg} / \mathrm{g})$ and $b\left(\mathrm{dm}^{3} / \mathrm{mg}\right)$ are the Langmuir constants relating to adsorption capacity and rate of adsorption, respectively, $q_{e}$ is the amount of MB adsorbed at equilibrium $(\mathrm{mg} / \mathrm{g})$ and $C_{e}$ is the liquid-phase equilibrium concentration $\left(\mathrm{mg} / \mathrm{dm}^{3}\right)$ [14].

The Freundlich adsorption isotherm is expressed by the following equations obtained on the assumption that multilayer adsorption takes place on a heterogeneous adsorbent surface [15]:

$$
\log q_{e}=\log K_{F}+\frac{1}{n} \log C_{e}
$$

where $q_{e}$ is the solid phase equilibrium concentration $(\mathrm{mg} / \mathrm{g}), C_{e}$ is the liquid-phase equilibrium concentration $\left(\mathrm{mg} / \mathrm{dm}^{3}\right), K_{F}$ and $n$ are Freundlich constants with $n$ giving an indication of the facility with which the adsorption process takes place. $K_{F}\left(\mathrm{mg} / \mathrm{g}\left(\mathrm{dm}^{3} / \mathrm{mg}\right)^{1 / n}\right)$ is the adsorption capacity of the adsorbent (i.e. the adsorption or distribution coefficient) and represents the quantity of dye adsorbed onto the olive pomace per unit of equilibrium concentration. The slope $1 / n$ ranging between 0 and 1 is a measure of the adsorption intensity or surface heterogeneity, $1 / n$ closer to zero, the more heterogeneous surface is. $1 / n<1$ indicates a normal Langmuir isotherm, while $1 / n>1$ is indicative of cooperative adsorption [16]. 


\section{RESULTS AND DISCUSSION}

\subsection{EFFECT OF CONTACT TIME AND ADSORBENT DOSAGES}

The removal of MB with ROP and MOP was studied at various adsorbent dosages $\left(200-800 \mathrm{mg} / \mathrm{dm}^{3}\right)$ of dye solution at a constant concentration $\left(100 \mathrm{mg} / \mathrm{dm}^{3}\right)$, stirring speed (250 rpm), $\mathrm{pH}(6)$ and contact time up to $300 \mathrm{~min}$.
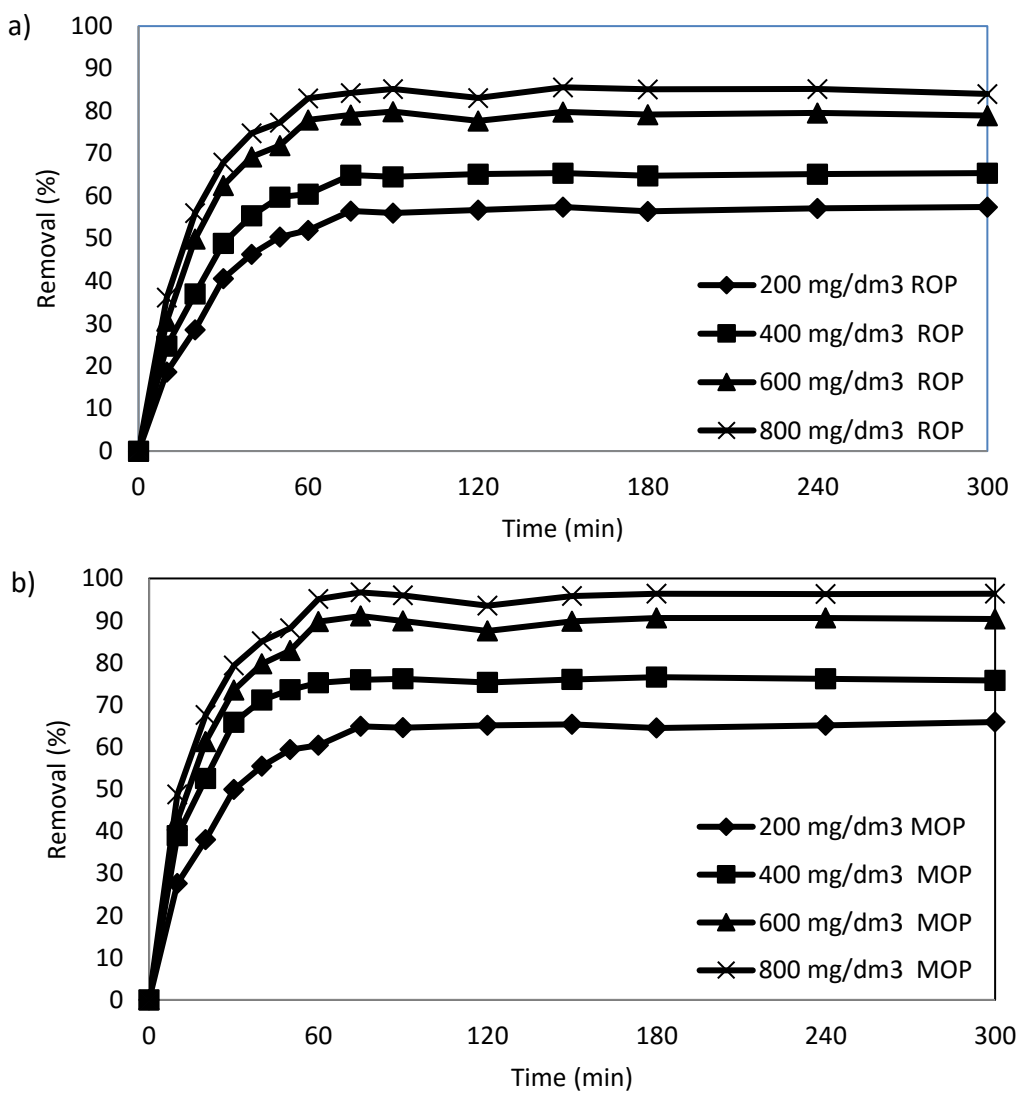

Fig. 3. Effect of time and dosage on the removal of $\mathrm{MB}$ $\left(100 \mathrm{mg} / \mathrm{dm}^{3}, \mathrm{pH}=6\right)$ by using of a) ROP, b) MOP

The effect of time and dosage of ROP on the removal of MB from aqueous solution is shown in Fig. 3a. An increase in the efficiency upon time was observed and the adsorption equilibrium was obtained after $75 \mathrm{~min}$. The equilibrium removal efficiencies at the ROP dosages of $200,400,600$, and $800 \mathrm{mg} / \mathrm{dm}^{3}$ were $56.5,64.9,79.1,84.3$, respectively. ROP was effective for the removal of MB and increase in the ROP dosage 
also increased available bonding sites on the surface of pomace and dye removal efficiency was increased due to binding of ions to more sites. These results correspond with those by Banat et al. [17].

A combination of olive pomace after solvent extraction and charcoal produced from the solid waste of olive oil press industry was used as an adsorbent for the removal of MB from aqueous solutions. Batch tests showed that up to $80 \%$ of dye was removed when the dye concentration was $10 \mathrm{mg} / \mathrm{cm}^{3}$ and the sorbent concentration was $45 \mathrm{mg} / \mathrm{cm}^{3}$. An increase in the olive pomace concentration resulted in better dye removal [17]. As can be seen in Fig. 3b, MOP was more effective for the removal of MB and increase in the amount of MOP also increased the removal efficiency. In the removal experiments carried out by using MOP in dosages of $200,400,600$, and $800 \mathrm{mg} / \mathrm{dm}^{3}$, the equilibrium removal efficiencies determined after $75 \mathrm{~min}$ of experiment were 64.9, $75.9,91.1,96.7$, respectively. Ultrasonic acid modification increased the removal efficiency by using MOP as a result of opening sites on the surface of the adsorbent for the adsorption. Ultrasonic radiation generates very strong hydromechanical shear forces in the liquid medium at the frequencies of $20 \mathrm{kHz}$. These forces extend the adsorption surface by increasing the pores on the surface of the adsorbent material. Thus, the adsorption capacity of the material is enhanced via ultrasonication $[8,9]$.

\subsection{EFFECT OF TEMPERATURE}

Upon increasing temperature the rate of diffusion of the adsorbate molecules across the external boundary layer and in the internal pores of the adsorbent particles increases, as a result of the reduced viscosity of the solution. In addition, the equilibrium capacity of the adsorbent for a particular adsorbate is also temperature dependent [18]. Temperature dependences of the removal efficiency of MB using ROP and MOP are shown in in Fig. 4.

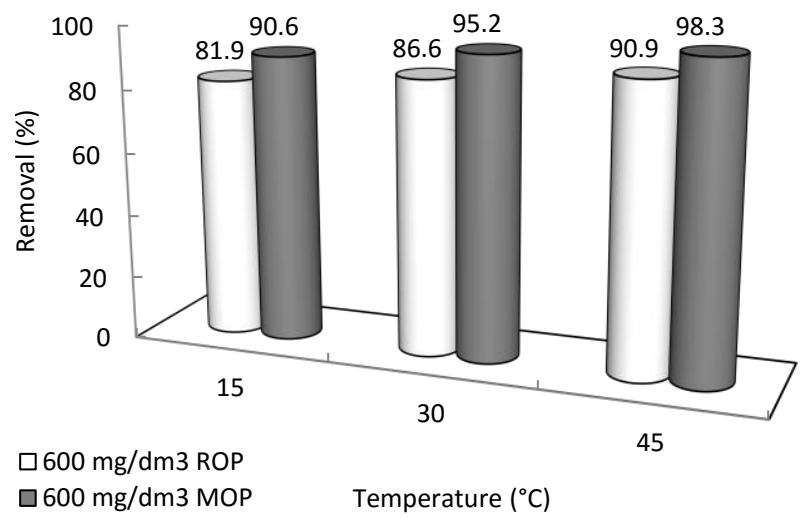

Fig. 4. Effect of temperature on the removal of MB $\left(100 \mathrm{mg} / \mathrm{dm}^{3}, \mathrm{pH}=6\right)$ by using ROP and MOP 
In a study carried out using graphite powder for the removal of MB, it was found that an increase in temperature resulted in an increase in the adsorption efficiency [19]. In the experiments carried out with ROP, increase in temperature only slightly increased the removal efficiency. This might be due to an increase in the chemical potential of dye molecules penetrating the surface of the pomace. The removal efficiencies for ROP were: $81.9 \%$ at $15{ }^{\circ} \mathrm{C}, 86.6 \%$, at $30{ }^{\circ} \mathrm{C}$, and $90.9 \%$ at $45^{\circ} \mathrm{C}$. The removal efficiencies for MOP were $90.6 \%$ at $15^{\circ} \mathrm{C}, 95.2 \%$ at $30^{\circ} \mathrm{C}$, and $98.3 \%$ at $45^{\circ} \mathrm{C}$. Due to weak temperature effect, the temperature of $30^{\circ} \mathrm{C}$ was found optimum for further experiments.

\subsection{EFFECT OF $\mathrm{pH}$}

The studies indicated that $\mathrm{pH}$ has a significant effect on the adsorption capacity [19]. The adsorption efficiencies determined at various $\mathrm{pH}$ are shown in Fig. 5. In the experiments carried out with ROP, the removal efficiencies were: $65.5 \%$ for $\mathrm{pH} 3,79.1 \%$ for $\mathrm{pH} 6,86.6 \%$ for $\mathrm{pH} 9$ and $89.9 \%$ for $\mathrm{pH} 12$. The removal efficiencies for MOP were:

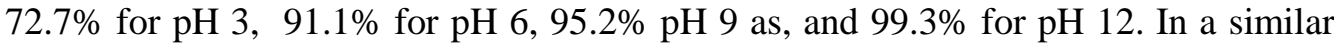
study, it was found that increase in $\mathrm{pH}$ increased negative charge at the surface and therefore an increase was observed in the adsorption capacity [19]. Increase in $\mathrm{pH}$ resulted in negative charging of the pomace surface with $\mathrm{OH}^{-}$ions and removal efficiency of cationic MB was enhanced.

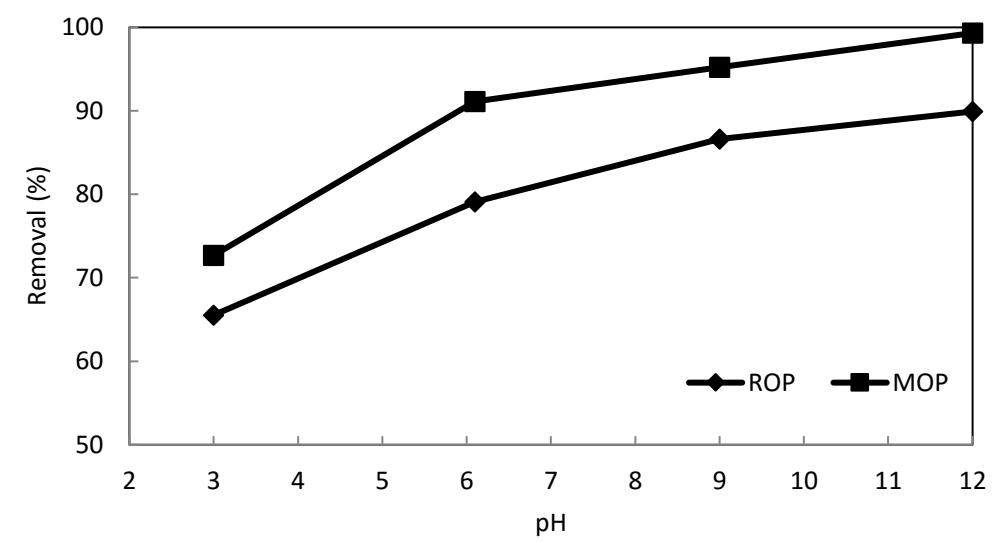

Fig. 5. Effect of $\mathrm{pH}$ on the removal efficiency of $\mathrm{MB}$ by using ROP and MOP (adsorbent dosage $=600 \mathrm{mg} / \mathrm{dm}^{3}, 30{ }^{\circ} \mathrm{C}, 250 \mathrm{rpm}$ )

\subsection{EFFECT OF STIRRING SPEED}

The dependence of removal efficiency on the stirring speed was examined at $30{ }^{\circ} \mathrm{C}$ for $75 \mathrm{~min}$, with ROP and MOP dosage of $600 \mathrm{mg} / \mathrm{dm}^{3}$, the dye concentration of $100 \mathrm{mg} / \mathrm{dm}^{3}$ at 200,250 and $300 \mathrm{rpm}$. The results are shown in in Fig. 6 . 


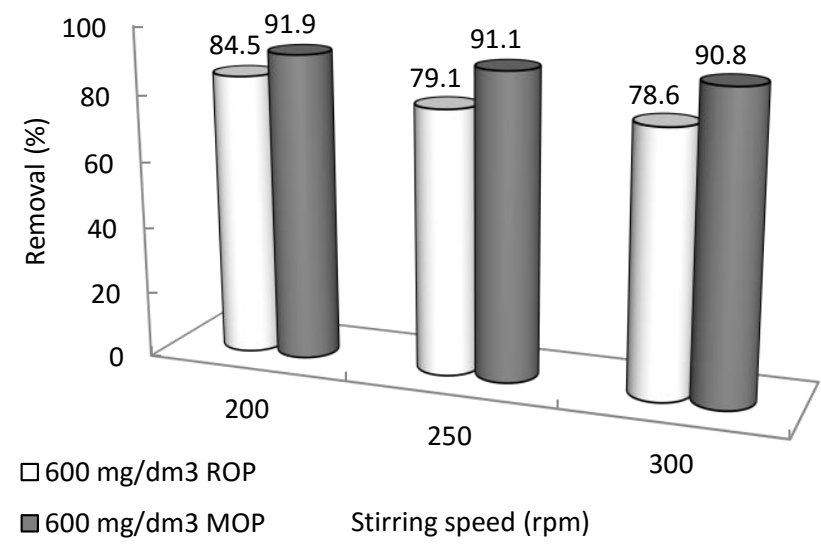

Fig. 6. Effect of stirring speed on the removal of MB by using ROP and MOP $\left(\mathrm{pH}=6, \mathrm{MB}\right.$ concentration $\left.=100 \mathrm{mg} / \mathrm{dm}^{3}\right)$

In the experiments, a significant increase of the removal efficiency upon increasing stirring speed has not been observed. For the removal of MB, the removal efficiencies by using $600 \mathrm{mg} / \mathrm{dm}^{3}$ of ROP at 200, 250, and $300 \mathrm{rpm}$ were $84.5,79.1,78.6 \%$, respectively. Under the same experimental conditions for MOP, they were 91.9, 91.1, 90.8\%, respectively. About $15 \%$ increase in dye removal was observed for the experiments carried out with MOP at $250 \mathrm{rpm}$ stirring speed when compared to ROP. Increase in stirring speed increased the contact of adsorbent with MB dye molecule by decreasing the density of diffusion layer around the adsorbent surface and resulted in an increase in the removal efficiency [20]. In the study of Garg et al. [21] performed for the removal of MB dye by using Indian Rosewood sawdust, similar results were reported for cationic dyes.

\subsection{ADSORPTION ISOTHERMS}

The adsorption isotherm basically reflects the interaction between solutes and adsorbents until the point where a state of equilibrium is reached. Various isotherm models, fitted to the isotherm data, have been reported in the literature [22] to optimize the effectiveness of adsorbents. In this study, fitting of experimental equilibrium data for MB removal by using ROP and MOP to Langmuir and Freundlich isotherm models was examined. In order to evaluate the ability of the models to describe the adsorption process, the correlation coefficients $\left(R^{2}\right)$ were calculated. Freundlich isotherms for the removal of MB by using ROP and MOP are shown in Fig. 7, and Langmuir isotherms - in Fig. 8. The parameters and correlation coefficients of the Freundlich isotherm for $\mathrm{MB}$ adsorption on ROP and MOP are given in Table 2. The experimental data for MB removal by using ROP $\left(R^{2}=0.864, K_{F}=10.08 \mathrm{mg} / \mathrm{g}\left(\mathrm{dm}^{3} / \mathrm{mg}\right)^{1 / n}\right)$ and $\operatorname{MOP}\left(R^{2}=0.834\right.$, $\left.K_{F}=73.08 \mathrm{mg} / \mathrm{g}\left(\mathrm{dm}^{3} / \mathrm{mg}\right)^{1 / n}\right)$ corresponded the Freundlich isotherm model. In other 
studies, it was found that MB adsorption by using palm kernel fiber [20] and neem leaf powder [23] better described the Freundlich isotherm model.

Table 2

Freundlich isotherm model parameters and correlation coefficients

for the adsorption of MB on ROP and MOP

\begin{tabular}{|l|c|c|}
\hline \multicolumn{1}{|c|}{ Parameter } & ROP & MOP \\
\hline $1 / n$ & 0.8404 & 0.3635 \\
\hline$K_{F,} \mathrm{mg} /\left(\mathrm{g}\left(\mathrm{dm}^{3} / \mathrm{mg}\right)^{1 / n}\right)$ & 10.08 & 73.08 \\
\hline$R^{2}$ & 0.8644 & 0.8344 \\
\hline
\end{tabular}
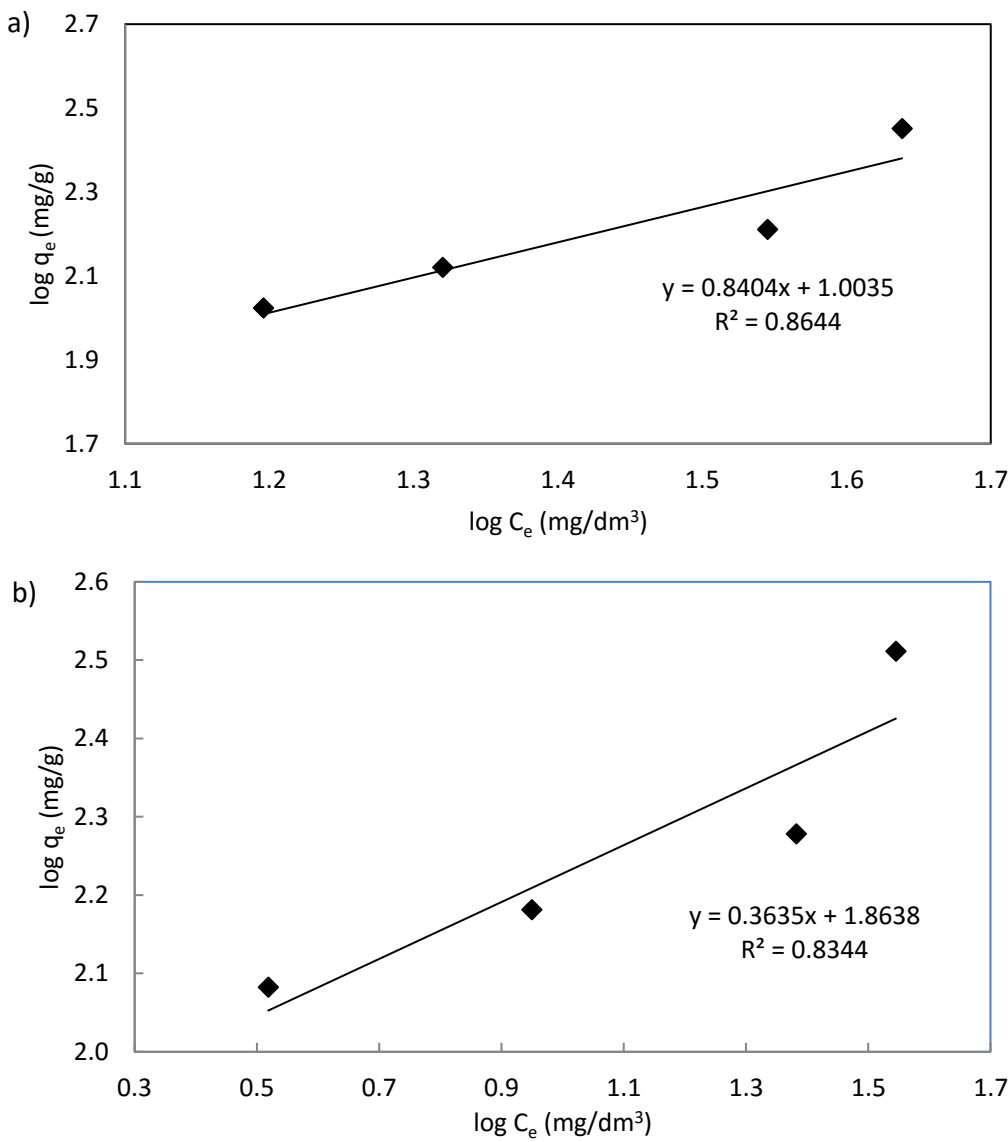

Fig. 7. Freundlich adsorption isotherms of methylene blue on a) ROP, b) MOP $\left(30^{\circ} \mathrm{C}, \mathrm{pH}=6,250 \mathrm{rpm}\right)$ 

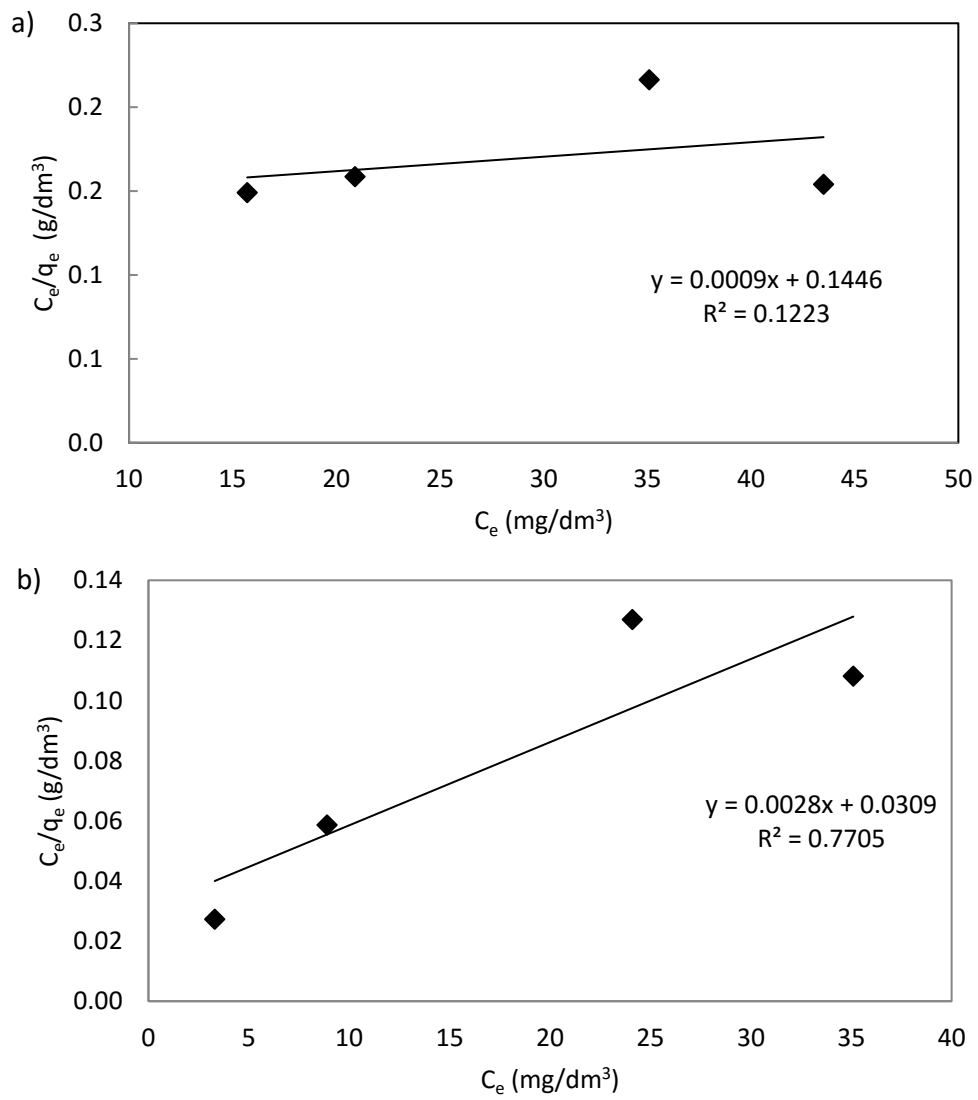

Fig. 8. Langmuir adsorption isotherms of MB on a) ROP, b) MOP $\left(30{ }^{\circ} \mathrm{C}, \mathrm{pH}=6,250 \mathrm{rpm}\right)$

In the experiments performed using MOP, the adsorption capacity $\left(K_{F}=73.08\right.$ $\left.\mathrm{mg} / \mathrm{g}\left(\mathrm{dm}^{3} / \mathrm{mg}\right)^{1 / n}\right)$ substantially increased when compared to the experiments carried out with ROP $\left(K_{F}=10.08 \mathrm{mg} / \mathrm{g}\left(\mathrm{dm}^{3} / \mathrm{mg}\right)^{1 / n}\right)$. Similar results have also been reported by Oyelude and Owusu [24] for the adsorption of MB dye onto acid modified Calotropis procera leaf powder. Thus, it was found that modification of olive pomace with ultrasounds and acid was a significant alternative method for the modification of the adsorbent. The combination of ultrasound and the adsorption process seems to be a promising technology for the removal of macromolecules such as dyes [25].

\section{CONCLUSIONS}

For the removal of methylene blue from aqueous solution, the adsorption potential of olive pomace, the industrial waste of olive oil industry, was examined as its raw and 
modified form with ultrasonic radiation for various adsorbent dosages, contact time, solution $\mathrm{pH}$, temperature, stirring speed and adsorption isotherms. The results are summarized as follows:

- Raw olive pomace can be used for the removal of MB dye and is also an effective adsorbent for the removal of cationic MB when it was used after modification. Ultrasonic and acid modification substantially increased the adsorption capacity of the olive pomace from $K_{F}=10.08 \mathrm{mg} / \mathrm{g}\left(\mathrm{dm}^{3} / \mathrm{mg}\right)^{1 / n}$ to $73.08 \mathrm{mg} / \mathrm{g}\left(\mathrm{dm}^{3} / \mathrm{mg}\right)^{1 / n}$.

- The adsorption of MB on ROP and MOP fits the Freundlich equilibrium isotherm.

- The adsorbent has some advantages since it is easily available, renewable, applicable in terms of region and has low cost.

\section{ACKNOWLEDGEMENTS}

This work was supported by Scientific Research Found (NEUBAP14F17) of Nevsehir Hac1 Bektas Veli University.

\section{REFERENCES}

[1] Ozdemir C., Oden M.K., Sahinkaya S., KaliPCi E., Color removal from synthetic textile wastewater by sono-Fenton process, Clean Soil Air Water, 2011, 39, 60.

[2] SAHINKAYA S., COD and color removal from synthetic textile wastewater by ultrasound assisted electro-Fenton oxidation process, J. Ind. and Eng. Chem., 2013, 19 (2), 601.

[3] GuRSES A., YAlCin M., Dogar C., Electrocoagulation of some reactive dyes: a statistical investigation of some electrochemical variables, Waste Manage., 2002, 22, 491.

[4] Robinson T., Mcmullan G., Marchant R., Nigam P., Remediation of dyes in textile effluent. A critical review on current treatment technologies with a proposed alternative, Bioresour. Technol., 2001, $77,247$.

[5] Gupta V.K., Mittal A., Jain R., Mathur M., Sikarwar S., Adsorption of Safranin-T from wastewater using waste materials activated carbon and activated rice husks, J. Colloid Interface Sci., 2006, $303,80$.

[6] Guru M., Venedik D., Murathan SeleK A., Removal of trivalent chromium from water using low costnatural diatomite, J. Hazard. Mater., 2008, 160, 318.

[7] EREN Z., Ultrasound as a basic and auxiliary process for dye remediation: A review, J. of Environ. Manage., 2012, 104, 127.

[8] Hamdaoui O., Naffrechoux E., Tifouti L., Pe'Trier C., Effects of ultrasound on adsorption-desorption of p-chlorophenol on granular activated carbon, Ultrason. Sonochem., 2003, 10, 109.

[9] Fernandes J.P.S., Carvalho B.S., LuChez C.V., Politi M.J., Brandt C.A., Optimization of the ultrasound-assisted synthesis of allyl 1-naphthyl ether using response surface methodology, Ultrason. Sonochem., 2011, 18, 489.

[10] Pagnanelli F., Mainelli S.. Veglio F., Michelis I.D., Beolchini F., Toro L., Olive pomace for heavy metal removal. Adsorbent characterisation and equilibrium modelling, Acta. Metall. Slovaca, 2006, 12, 313.

[11] ERguder T.H., Guven E., DemiRer G.N., Anaerobic treatment of olive oil mill wastes in batch reactors, Process Biochem., 2000, 36, 243.

[12] Almeida C.A.P., Debacher N.A., Downs A.J., CotTet L., Mello C.A.D., Removal of methylene blue from colored effluents by adsorption on montmorillonite clay, J. Coll. Interface Sci., 2009, 332, 46. 
[13] Alkan M., Demirbas O., Dogan M., Adsorption kinetics and thermodynamics of an anionic dye onto sepiolite, Micropor. Mesopor. Mater., 2007, 101, 388.

[14] Weber W., Digiano F., Process Dynamics in Environmental Systems, Wiley, 1st Ed., New York 1996.

[15] Freundlich H.M.F., Over the adsorption in solution, J. Phys. Chem., 1906, 57, 385.

[16] Fytianos K., Voudrias E., KoKKalis E., Sorption-desorption behaviour of 2,4-dichlorophenol by marine sediments, Chemosphere, 2000, 40, 3.

[17] Banat F., Al-Asheh S., Al-Ahmad R., Bni-Khalid F., Bench-scale and packed bed sorption of methylene blue using treated olive pomace and charcoal, Bioresour. Technol., 2007, 98, 3017.

[18] Dogan M., Alkan M., Turkyilmaz A., OzDEMIR Y., Kinetics and mechanism of removal of methylene blue by adsorption onto perlite, J. Hazard. Mater., 109, 2004, 141.

[19] Zнао M., LiU P., Adsorption of methylene blue from aqueous solutions by modified expanded graphite powder, Desalination, 2009, 249, 331.

[20] EL-SAYED G.O., Removal of methylene blue and crystal violet from aqueous solutions by palm kernel fiber, Desalination, 2011, 272, 225.

[21] GARG V.K., Amita M., Kumar R., GuPTA R., Basic dye (methylene blue) removal from simulated wastewater by adsorption using Indian Rosewood sawdust: a timber industry waste, Dyes Pigm., 2004, 63, 243.

[22] DE D.S., BASU J.K., Adsorption of methylene blue onto a low cost adsorbent developed from saw dust, Ind. J. Environ. Protec., 1998, 19, 416.

[23] McKay G., Ramprasad G., Pratapamowli P., Equilibrium studies for the adsorption of dyestuffs from aqueous solution by low-cost materials, Water Air Soil Pollut., 1986, 29, 273.

[24] OYELUDE E.O., OWUSU U.R., Adsorption of methylene blue from aqueous solution using acid modified Clotropis procer leaf powder, J. Appl. Sci. Environ. Sanit., 2011, 6, 477.

[25] Sonawane S.H., Chaudhari P.L., Ghodke S.A., Parande M.G., Bhandari V.M., Mishra S., KULKARNI R.D., Ultrasound assisted synthesis of polyacrylic acid-nanoclay nanocomposite and its application in sonosorption studies of malachite green dye, Ultrason. Sonochem., 2009, 16, 351. 